\title{
El factor de innovación fundamentado en la identidad ancestral aplicado en emprendimientos de diseño y de turismo comunitario
}

\section{The factor of innovation based on the ancestral identity applied in design and community tourism ventures}

Burneo Villamagua Jeamil

Trelles Ordóñez Daniela

Universidad Internacional del Ecuador, Ecuador

Autor para correspondencia: jeburneosa@internacional.edu.ec; datrellesor@internacional.edu.ec

Fecha de recepción: 10 de abril de 2018 - Fecha de aceptación: 15 de septiembre de 2018

Resumen: Analizamos las potencialidades que tiene el diseño con identidad para generar un producto cultural que sea representativo de Loja y que potencie además el desarrollo del turismo comunitario en un sitio con alto interés cultural y con características puntuales favorables para el desarrollo de la investigación. En el trabajo académico, el proceso de diseño busca desarrollar nuevos elementos y productos de diseño que nacen de la investigación iconográfica de los pueblos originarios que nos permitan generar un elemento identificador del sitio arqueológico y que sea trasferido a los artesanos del sector. Las experiencias en las aulas relacionadas con proceso de creación de patrones gráficos y prototipos de diseño son analizadas en el desarrollo del artículo, su validación preliminar de mercado con el objetivo de generar su futura producción y fabricación en diferentes gamas artesanales que permita que pequeños emprendimientos produzcan de manera adecuada. Focalizamos el ámbito de estudio en el sitio "Tambokocha" cercano a la ciudad de Loja, para determinar algunas concreciones respecto de la influencia que tendría la revitalización cultural prevista hacia el manejo inicial de un atractivo de turismo comunitario en dicho sector. Rescatamos la simultaneidad del trabajo teórico y conceptual con la fabricación de prototipos de los productos generados, los cuales han sido presentados en eventos de emprendimiento y exposiciones en instancias universitarias y comerciales, los aprendizajes de dichas actividades son concluyentes respecto a la viabilidad y aceptación de la producción creativa y de su injerencia sobre actividades turísticas relacionadas con la cultura.

Palabras clave: innovación; saberes ancestrales; emprendimiento; diseño; innovación; turismo comunitario; iconografía

\begin{abstract}
Analyze the potential of design with identity to generate a cultural product that is representative of Loja and that also promotes the development of community tourism in a site of high cultural interest and with specific characteristics favorable to the development of research. In the academic work, the design process seeks new design elements and products that are born from the iconographic research of the indigenous peoples that allow us to generate an element that identifies the archaeological site and that is transferred to the artisans of the sector. The experiences in the classrooms related to the process of creating patterns and design prototypes are analyzed in the development of the article, its preliminary validation of the market with the aim of generating
\end{abstract}


its future production and manufacturing in different craft ranges that allow small businesses Produce correctly. We focused on the scope of the study on the site "Tambokocha", near the city of Loja, to determine some concretions regarding the influence of cultural revitalization related to the initial management of a community tourism sector in that place. We rescue the simultaneity of the conceptual theoretical work with the manufacturing of prototypes of the generated products, which have been presented in entrepreneurship events and exhibitions in the university and commercial instances, the apprentices of the activities are the conclusive ones regarding the viability and acceptance of production creative and its interference in activities related to culture.

Key words: innovation; ancestral knowledge; entrepreneurship; design; innovation; community tourism; iconography

\section{Introducción}

Estamos seguros de las potencialidades que tiene el diseño con identidad para generar un producto cultural que sea representativo de Loja. Las representaciones iconográficas de nuestros pueblos originarios tienen la enorme potencialidad de convertirse en la base para una creación original, coherente, de alto valor cultural y estético, como plantea (Còrdova, 2016). "permitirá demostrar el enlace entre la geometría sagrada andina, los artefactos artísticos de ese pueblo y su época y su resonancia continua hasta la contemporaneidad en base a la filosofía andina que se ha permeado en el tiempo, generando otras formas de creación artística con profundos elementos semióticos, filosóficos, artísticos y geométricos, todos basados en la interconexión". Lastimosamente en Ciudadela no se realizado un proceso de sistematización y en la actualidad es incipiente la producción artesanal que presente una investigación rigurosa para transmitir su cultura y cosmovisión. Igualmente percibimos una falencia al desarrollar productos de difusión gráfica que representen la cultura ancestral, la cual se puede plasmar en productos de diseño desde una escala menor a una mayor, revitalizando además la cultura con nuevos íconos nuevos a ser aplicados en objetos (artesanías, interiorismo, home deco), en la arquitectura local y el urbanismo.

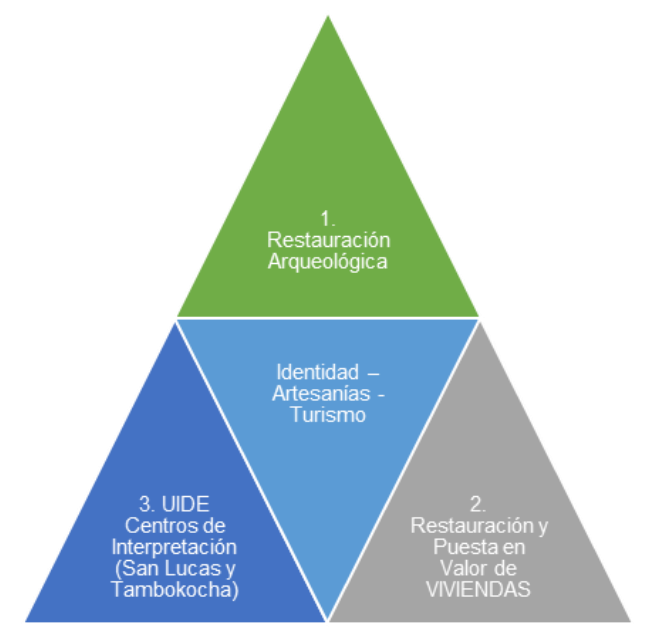

Cerca de la ciudad de Loja, existe un sitio arqueológico de mucha importancia, lastimosamente poco conocido debido a que no se ha planteado la puesta en valor cultural del bien arqueológico patrimonial. La UIDE ha desarrollado el componente 3 del gráfico adjunto, 
con dos estudios arquitectónicos de Centros de Interpretación ubicados en las cercanías de los vestigios arqueológicos de Tambokocha y en San Lucas, de dicha información creemos que necesario por fases ir desarrollando las actividades 1 y 2 , en cuyo caso la intervención de las instituciones correspondiente es un imperativo. El aporte de nuestra investigación se desarrolla en el tema central de Identidad y desde esa lógica alimentaría a los otros componentes del Proyecto integral (Guamán Guamán, D. M.; 2017).

El proceso de diseño e interpretación iconográfico aporta con la creación de patrones gráficos, generando prototipos de diseño, posibilitando su futura producción y fabricación. La incorporación de los saberes ancestrales y la identidad para crear patrones de diseño contemporáneo que puede ser expresado en producción de productos en diferentes gamas artesanales que permita que pequeños emprendimientos produzcan de manera adecuada. El proyecto busca transmitir la memoria histórica de los pueblos originarios del sitio arqueológico de Tambokocha, a través de productos de diseño, creando una marca local con alto valor estético, funcional y cultural, que permita revitalizar la identidad y sentido de pertenencia a la comunidad. El desarrollo de un modelo de gestión turística sostenible en el lugar determina una aplicación de turismo comunitario.

\section{Objetivo General}

Producir productos con identidad, relacionados con el diseño conjuntamente con promover la investigación, apropiación y recreación de la cultura de los pueblos originarios del sitio arqueológico de Ciudadela (Tambokocha) para la creación de propuestas gráficas, enfocadas a potenciar el enriquecimiento cultural y el desarrollo local.

\section{Objetivos Específicos}

- Identificar la iconografía de los pueblos originarios del sitio arqueológico de Ciudadela (Tambokocha), para que el conocimiento obtenido se incorpore en la producción nacional.

- Analizar la semiótica de las culturas originarias en el sitio arqueológico de Ciudadela (Tambokocha)

- Impulsar la generación de investigación científica, innovación, emprendimiento, y revalorización de los saberes ancestrales.

- Aportar sobre la existencia de un proyecto de diseño arquitectónico del centro de interpretación cultural in situ, con un guion de manejo del elemento patrimonial para desarrollar turismo comunitario.

\section{Metodología}

\section{Propuesta de Valor}

El proyecto pretende aportar con la creación de patrones gráficos, generar prototipos de diseño, posibilitando su futura producción semi-industrial con la colaboración de diversas instituciones e instancias, para la aplicación en el diseño. 
"Nuestras culturas originarias poseían un rico lenguaje visual, por lo que éste puede ser implementado en el diseño contemporáneo; estos dos, pueden ser el lazo perfecto para que la academia a través de la investigación, se vincule con la comunidad realizando un diálogo de saberes, actividad que se busca potenciar en el territorio ecuatoriano. A su vez, generando desarrollo económico, mediante la producción de objetos con valor agregado (Sacha, 2014)".

El reto del proyecto fue promover la investigación, apropiación y recreación de la cultura de los pueblos originarios de Loja para la creación de propuestas gráficas enfocadas a potenciar la cultura y el desarrollo local.

Se busca entonces transmitir la memoria histórica cultural a los habitantes de Loja, de la región y el país, a través de productos de diseño, creando una marca local (Criado, E. A. ; 2007) funcional y cultural, de igual manera busca la apropiación social del patrimonio cultural, que permita a la academia el relacionamiento adecuado a los artesanos, diseñadores, productores, micro y medianas empresas artesanales, que permita generar mayor valor agregado en sus niveles de producción y comercialización.

La pregunta de investigación con la cual nace este proyecto, es: ¿la labor de la universidad permite identificar, desarrollar nuevos esquemas gráficos y utilizar la iconografía de las culturas originarias para crear diseños contemporáneos aplicables en la artesanía, arquitectura y urbanismo?

Al describir los sustentos iconográficos y simbólicos de las culturas originarias se posibilita la actividad creativa de lenguajes artísticos nuevos pero con raíces culturales e históricas, buscando así crear fortalecer la identidad cultural, incentivando el turismo, el emprendimiento, la innovación por ende el desarrollo local y regional. Los pueblos ancestrales produjeron en el pasado aborigen, e incluso mantuvieron y recrearon hasta el presente un importante patrimonio cultural que constituye la producción identitaria más profunda lograda en el país. Este patrimonio, particularmente las representaciones iconográficas, tienen la enorme potencialidad de convertirse en la base para una creación original, coherente, de alto valor cultural y estético. "Según los ancianos sabedores todos nacemos con facultades artísticas, pero algunos las desarrollan mejor que otros...todos podemos realizarlos, pero no todos los podemos hacer con los mismos saberes ni con el mismo arte; con esto ellos quieren significar que en todos nuestros actos se reflejan los pensamientos, sentimientos y la voluntad con que se obra". (Muchavisoy, J., \& Narciso, J.; 1997).

Precisamente el proyecto pretende aportar con la creación de patrones gráficos, generar prototipos de diseño, posibilitando su futura producción semi-industrial con la colaboración de diversas instituciones e instancias, para la aplicación en el diseño. Está producción semiindustrial busca cumplir el segundo objetivo del plan nacional de buen vivir: "Mejorar las capacidades y potencialidades de la ciudadanía"; ya que el proyecto busca que el conocimiento generado en la academia se integre a los intereses

planteados por el Estado ecuatoriano, con el fin de crear desarrollo cultural, fomentando el emprendimiento y brindado capacitación a nuestros artesanos.

\section{Marco Conceptual}


El sustento conceptual del proyecto, vincula en primera instancia conceptos como fenomenología e iconografía, con el objeto de determinar el punto creativo de partida para generar elementos de diseño relacionados con la percepción subjetiva de las emociones y por otro lado la correlación con elementos iconográficos de las culturas originarias.

El historiador y crítico de arte Erwin Panofsky (Studies in Iconology -"Estudios sobre iconología"-, 1939) definía "iconografía" como "la rama de la Historia del Arte que se ocupa del contenido temático o significado de las obras de arte en cuanto algo distinto de su forma"; y estableció un "método iconológico" (Panofsky, 1939), para ello, en tres pasos:

A. Sensorial que es la descripción pre iconográfica, únicamente sensorial.

B. Identificación descriptiva de imágenes, historias y alegorías dentro de una obra, llamado análisis iconográfico.

C. Interpretación de acuerdo con el contexto cultural, social e histórico, denominado análisis iconológico.

En el caso de los pueblos originarios andinos, existen elementos iconográficos muy antiguos, algunos cobijados bajo los estratos más profundos y entre los escombros de cuatro mil ochocientos años de barro y piedra, vida y muerte, polvo y tiempo, "en el caso del Ayni" fueron apareciendo lentamente dos antebrazos cruzados moldeados en arcilla y oro, como inédita alegoría que por su antigüedad y enigmático contenido no tenían parangón cronológico con las iconografías sagradas de otras culturas del mundo.

El diseño de la Cruz Cuadrada Escalonada surge de un sofisticado proceso geométrico para cuadrar el círculo y hallar la relación entre la circunferencia y su diámetro, relación nomenclaturada como "Pi" por occidente y como KATARI por nosotros los andinos. (Milla Villena, C.; 2003).

\section{Proceso De Diseño}

Siguiendo la metodología presentada por la fundación Sinchi Sacha (Sacha, 2014), el proceso de diseño seguirá 3 fases:

Fase 1: Identificación de la iconografía de los pueblos originarios, reconocimiento de los lugares donde éstas se encontraron, para luego realizar la geometrización de éstas.

Fase 2: Se analizará la semiótica de estos signos, describiendo el concepto de las formas usadas en cada signo, finalmente se intentará realizar un vocabulario visual de los pueblos originarios considerados. Una de las partes fundamentales de esta fase es la creación de patrones gráficos.

Fase 3: En esta fase se realizará el proceso creativo de diseño, para lo cual nos basaremos en los patrones gráficos obtenidos en la fase 2 de la investigación. En este punto, diseñaremos productos para la producción artesanal, que tenga como objetivo posterior la producción semi industrial. Se establecerán normas de calidad para el proceso de producción por categorías, para 
que después se proceda ya con la producción y comercialización en al menos una de las categorías.

\section{Fase 1. Identificación de la iconografía de los pueblos originarios}

"El universo permanentemente emite señales y signos a los habitantes andinos, quienes para entender a cabalidad estos mensajes deben, con frecuencia, recurrir a los amautas y a los abuelos. Un mensaje cotidiano que tiene la naturaleza para comunicarse con los habitantes de una determinada región es el lenguaje cósmico para determinar el ciclo agrícola, pues a través de él, claramente se indica las fechas más adecuadas para roturar la tierra, prepararla, proceder con la siembra, acompañar su desarrollo y crecimiento, para finalmente efectuar la cosecha, que determinará la situación económica de la comunidad mediante la abundancia o escasez de los productos agrícolas cosechados." (Brun, H. Z.; 2009).

El diseño es un proceso de creación visual con un propósito, o la mejor expresión visual de algo ya sea esto un mensaje o un producto donde el diseñador debe buscar la mejor forma posible para que se algo sea conformado, fabricado, distribuido, usado y relacionado con su ambiente.

La identidad es la síntesis que cada uno hace de los valores y de los indicadores de comportamientos transmitidos por los diferentes medios a los que pertenece. Integra esos valores y esas prescripciones según sus características individuales y su propia trayectoria de vida. La identidad es considerada como un fenómeno subjetivo, de elaboración personal, que se construye simbólicamente en interacción con otros. La identidad personal también va ligada a un sentido de pertenencia a distintos grupos socio- culturales con los que consideramos que compartimos características en común.

\section{Fase 2. Análisis Semiótico, Realización De Un Vocabulario Visual, Creación De Patrones Gráficos, Geometrización.}

El diseño (designar) es una disciplina inherente al proceso creativo funcional de todo producto cultural (comunicacionales, arquitectónicos, artesanales, artísticos e industriales), sustentada en procesos semióticos, mayor o menormente conscientes, mediante los cuales proyecta estratégicamente sus materiales, formas, signos y discursos. El Arte es la manifestación estética física de la obra.

La Semiótica del Diseño Andino constituye así una metodología de análisis de la significación de objetos culturales a partir del análisis contextualizado de sus formas y construcciones. Sus correlatos son de carácter holístico e intercultural. Su finalidad es el conocimiento de los códigos (qellcas), lenguajes y procesos funcionales, espaciales, simbólicos y estéticos subyacentes en los discursos del diseño y el arte andino. (Milla Euribe, Z.; 1990.

Se realiza un análisis previo de cada simbología, teniendo en cuenta su representación simbólica y valoración dentro de la cultura que se encuentran. 


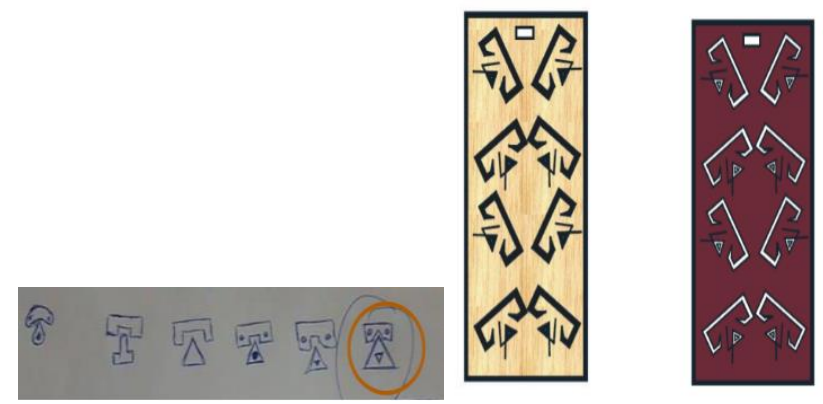

Figura Nro.1: Proceso de creación de patrones gráficos desde la iconografía.

\section{Fase 3. Diseño De Productos Para La Producción}
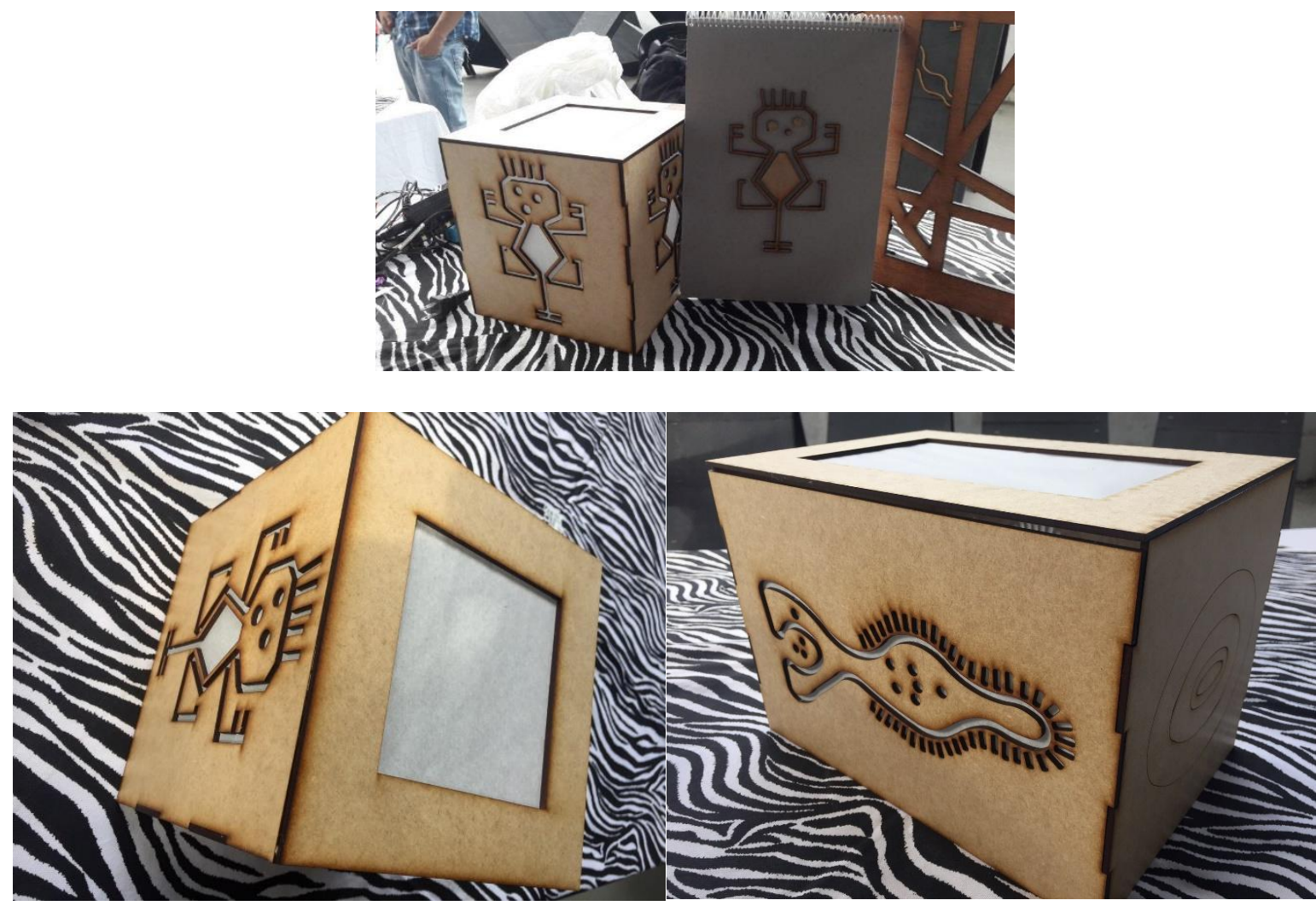

Figura Nro.2: Diseños HOMEDECO con identidad

Diseño: Estudiantes del Ciparq UIDE

\section{Fase 4. Análisis De Mercado}

Debemos contrastar además la percepción del diseñador, con las herramientas de validación de marcado realizadas con un tablero de experimentación Javelin, específicamente en el segmento Souvenirs Con Identidad.

Dicho tablero, es una herramienta que está diseñada para plantear hipótesis y desarrollar experimentos que nos permitan validar o refutar las mismas, mediante la creación y ejecución de 
ciclos de experimentación y pruebas. Además evita el derroche de tiempo y dinero requerido para el desarrollo de un producto que nadie quiere. (Chañi Choquemaque, M.; 2017).



Figura Nro.3: Tablero JAVELIN souvenirs con identidad

Se hace uso de esta metodología para saber si la acogida de la idea de utilizar la iconografía ancestral procedente de Loja como diseño de souvenirs con identidad tiene aceptación, se realizaron entrevistas informales a turistas y a funcionarios de instituciones públicas y privadas con la modalidad "escuchar al cliente". Para que el emprendimiento de resultados positivos debería tener una acogida del mercado de un $70 \%$ (validación). clientes:

Se realizaron dos preguntas importantes en una conversación informal con los posibles

1ra Pregunta: ¿Cuál crees que sería un obsequio adecuado para llevar a una persona que no conozca Loja que sea propio de esta ciudad y que la caracterice como tal?

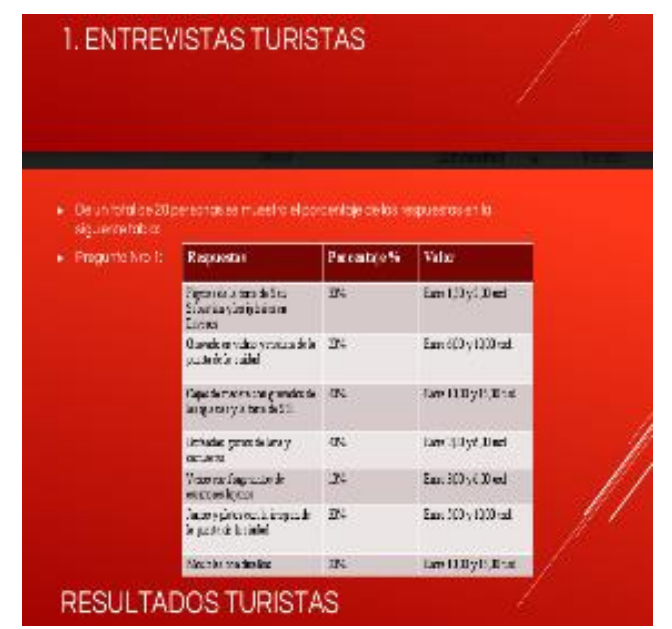

Figura Nro.4: Respuestas a pregunta 1 de turistas.

2da Pregunta: ¿Estarías dispuesto a comprar un objeto con motivos iconográficos ancestrales característicos de Loja? En la respuesta sólo se recibió una respuesta positiva del $30 \%$ de los entrevistados. 


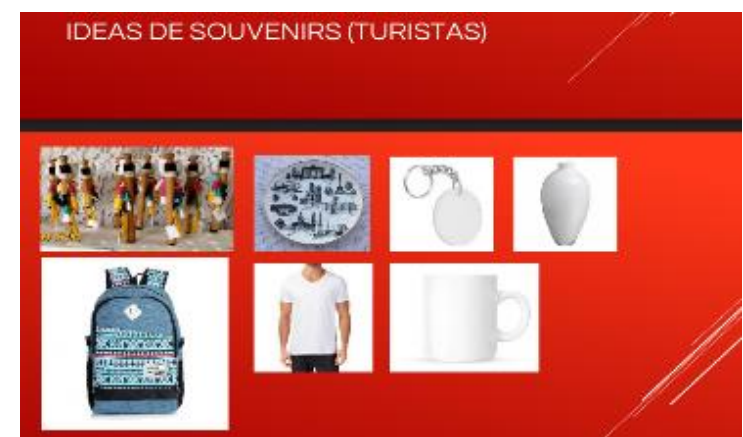

Figura Nro.5: Ideas de souvenirs requeridos por turistas en Loja.

En el otro segmento de mercado y clientes priorizado en el tablero Javelin, se consideran las instituciones de Loja. De 4 de ellas se valida en este caso con un 75\% las mismas preguntas realizadas al segmento anterior. De las sugerencias planeadas en souvenirs específicos a producirse para ellos, tenemos: Botellas con motivos de la ciudad. La imagen del teatro nuevo de Loja y del teatro Simón Bolívar. EL reloj de San Sebastián. La imagen de la institución. Los símbolos encontrados en las ruinas de ciudadela y lugares arqueológicos de San Lucas.

Conclusiones Del Javelin:

- Para poder generar el emprendimiento de los souvenirs con identidad lojana lo primero que se debe hacer es concientizar a la ciudadanía sobre la importancia de rescatar nuestras raíces ancestrales y generar un sentimiento de apropiación.

- Mientras no haya interés por parte de la mayoría de personas el proyecto será bien visto solo por conocedores del tema.

- La validación se da sólo en el caso de las instituciones con un 75\%, versus la percepción de los turistas que prefieren otros motivos o íconos simbólicos ya posicionados en Loja.

- La conclusión más importante se refiere a replantear el producto, y dotar de valores agregados a las piezas de diseño como por ejemplo generar una plataforma tecnológica en la Web en donde se ubiquen los lugares de origen y vestigios que sirven de inicio del proceso, para determinar una marca de origen.

A continuación se adjuntan imágenes de algunos prototipos en esa línea:

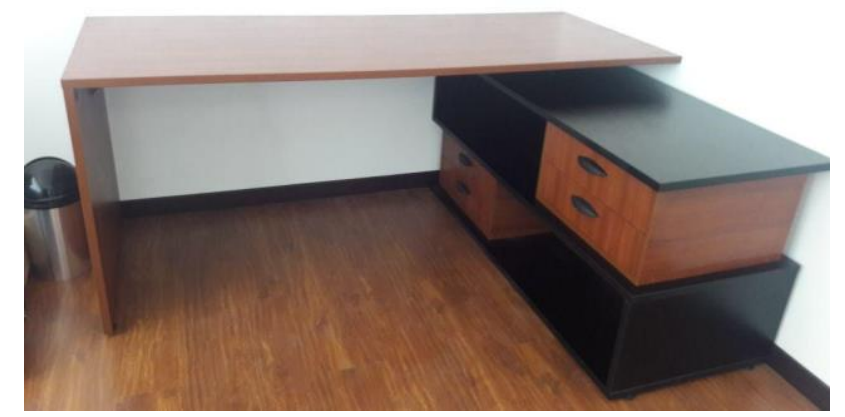

Figura Nro.6: Diseños de muebles con identidad en madera Diseño: Estudiantes del Ciparq UIDE 


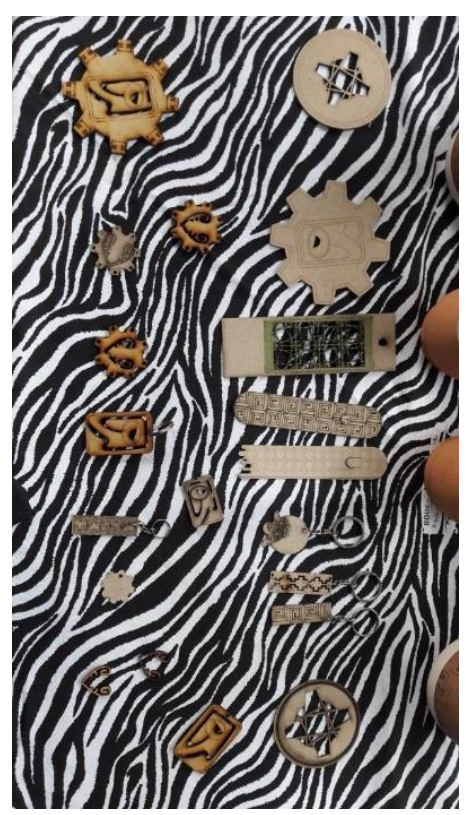

Figura Nro.7: Diseños de souvenirs con identidad en cerámica.

Diseño: Estudiantes del Ciparq UIDE

De dichos productos se establecerán normas de calidad para el proceso de producción en las categorías antes referidas, para que después de terminada la investigación se proceda ya con la producción y comercialización en al menos la mitad de las categorías mencionadas, de inicio. Producción y comercialización es la etapa final del proyecto. En esta fase, es importante mencionar la necesidad de incorporar el I+D de las universidades a través de sus estudiantes por un lado y por otro lado la posibilidad de trasferir las experiencias de cada parte éxitos del proceso, hacia la comunidad, como planteábamos el inicio del presente trabajo, hacia los artesanos y diseñadores de la provincia de Loja para conseguir una correlación en dos vías de aprendizaje mutuo.

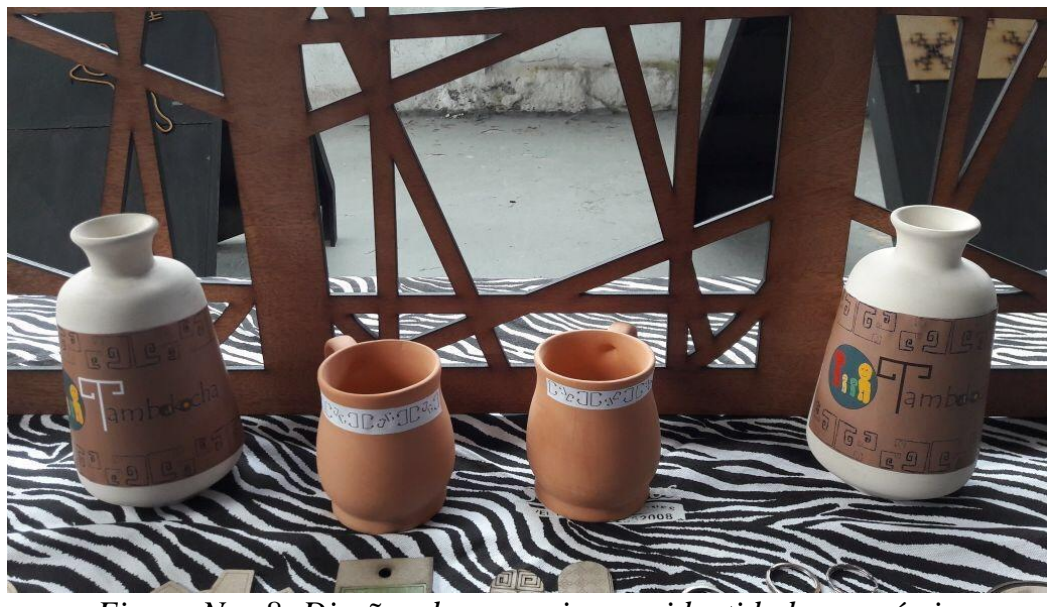

Figura Nro.8: Diseños de souvenirs con identidad en cerámica.

Diseño: Estudiantes del Ciparq UIDE 


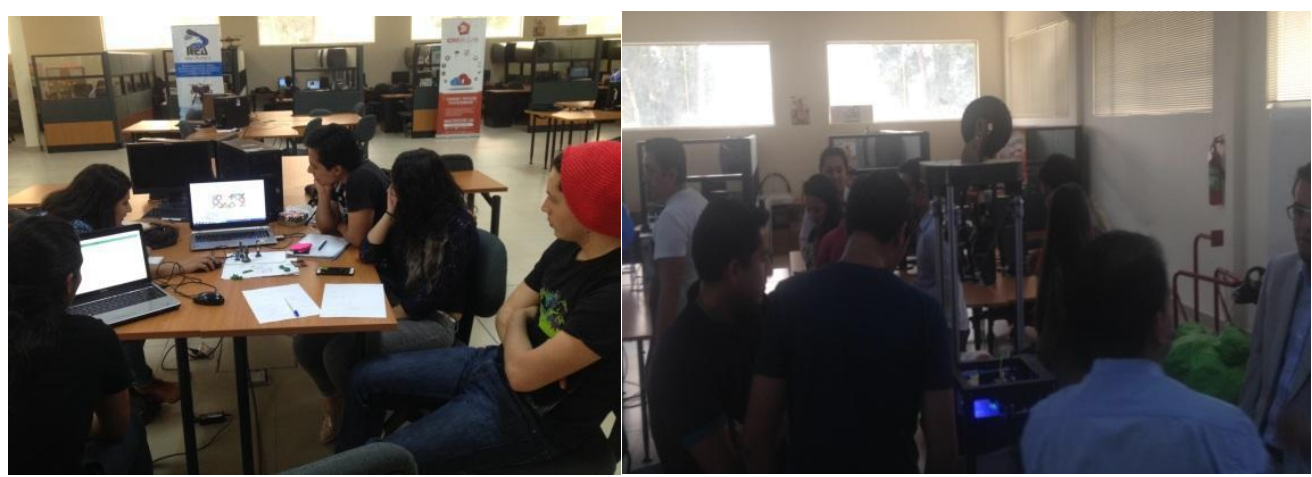

Figura Nro.9: Estudiantes del Ciparq UIDE desarrollando su emprendimiento, impresora $3 D$ en fase de fabricación

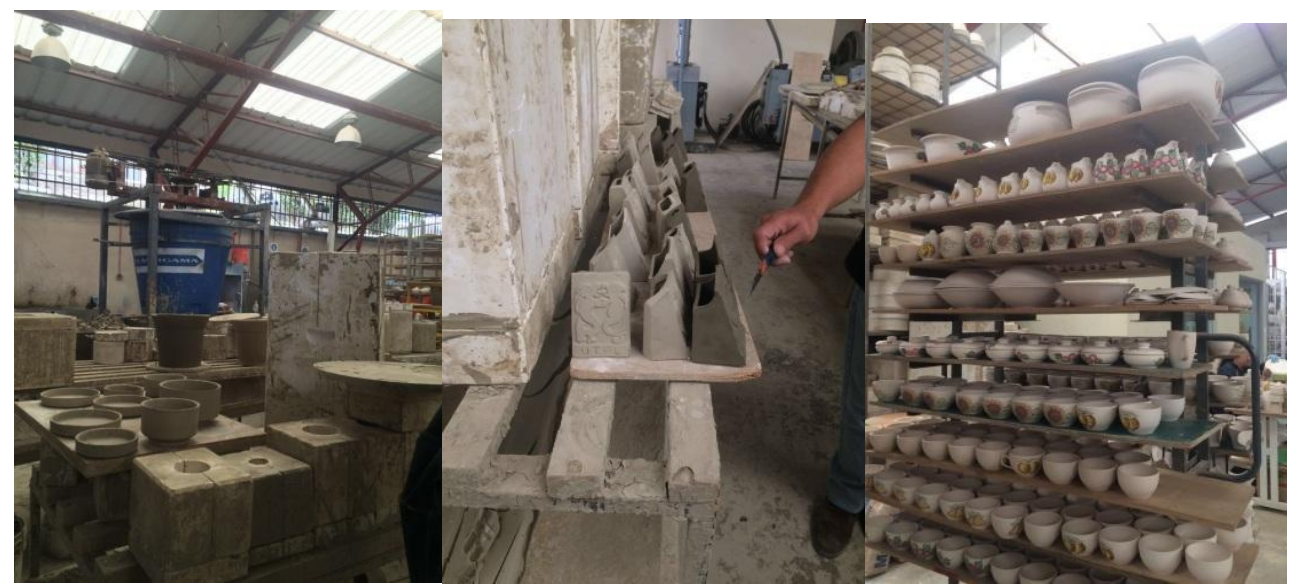

Figura Nro.10: Expresión en cerámica como potencial aporte al desarrollo de emprendimientos de diseño y trasferencia a artesanos lojanos.

\section{Fase 5. Generación De Atractivo Turístico Cultural.}

En esta fase, que aún no ha sido implementada, pretendemos generar un equipo multidisciplinario de especialistas de la UIDE, con el objeto de plantear propuestas de aplicación en el ámbito del turismo comunitario. La simbiosis turismo y patrimonio, se ha ido fortaleciendo y consolidando con el transcurrir de los años, promoviendo la revalorización de los sitios ancestrales a través de una visión intercultural cooperativa, cuyo objetivo principal es analizar, fortalecer y potenciar los recursos arqueológicos del sitio "Tambokocha" para convertirlos en un producto turístico interesante y atractivo, que pueda generar el interés de visitantes locales, nacionales y extranjeros, contribuyendo a la dinamización económica del sector.

Con este precedente es como se ha dado origen a una de las modalidades más enriquecedoras de la industria de los viajes, pues nos referimos al Turismo Cultural, de manera que es importante analizar, la definición del mismo que la Organización Mundial de Turismo, señala: "Son todos los movimientos de personas para satisfacer la humana necesidad de diversidad, orientados a elevar el nivel cultural del individuo, facilitando nuevos conocimientos, experiencias y encuentros" (OMT, 1985).

El sitio arqueológico Ciudadela Tambokocha, tiene una ubicación privilegiada, se emplaza en un mayores centros culturales y del saber ancestral de Loja relacionado, un rincón 
con una vasto componente cultural, cuya etnia Saraguro ha sido un elemento icónico, conservando sus costumbres, tradiciones y festividades a pesar de los años, manteniéndolas latentes y transmitiéndolas de generación en generación, situación que mejora las condiciones particulares del sector para efectuar actividades de Turismo Cultural, como un importante alternativa de desarrollo local.

El valor arqueológico de Tambokocha, resitúa la idea de proyección social, considerando a la cultura como el elemento clave para la proyección de los pueblos y entendiéndose como el núcleo fundamental sobre el cual se entreteje la memoria étnico histórica de una localidad, así las representaciones iconográficas identificadas en el lugar, van tomando representatividad para convertirse en símbolos artesanales, que conjugan un alto valor cultural y estético, por medio de la creación original y coherente de distintos souvenirs formativos culturales que transmiten la identidad, valor y proyección de un pueblo ancestral, es idóneo considerar que cada territorio tiene su esencia, que se relaciona con los significados, las identidades, los habitantes y su espiritualidad, y que se deriva también de la base natural de los lugares, cuya memoria histórica se hace presente haciendo un fuerte aporte, que permitirá avizorar un nuevo destino a las generaciones actuales, a través de la oportunidad de puesta en marcha de proyectos turísticos, centrados principalmente en la realización de un turismo vivencial, que comunique las vivencias de un pueblo ancestral que desea perpetuarse hacia el mañana.

Una de las alternativas de desarrollo local en el sitio, sería la construcción en el sitio del centro de interpretación diseñado por la escuela de arquitectura de UIDE, el cual puede ser operado por la comunidad, constituyéndose en un atractivo turístico contemporáneo que comunique didácticamente a visitantes y turistas el legado cultural de Tambokocha, en su museografía y esquema narrativo. En este cometido, también se ha proyectado arquitectónicamente un centro de interpretación en San Lucas, la cabecera parroquial, en cuyo caso se debe generar un libreto que coordine los contenidos y relaciones de los dos espacios culturales para favorecer el posicionamiento del lugar arqueológico en estudio.

Interpretar el patrimonio requiere un enfoque participativo y sistémico, que esencialmente debe poseer lo siguiente:

1. Comunicar la esencia del lugar, basada en los saberes locales y en el conocimiento de los hechos y situaciones principales.

2. Difundir el mensaje formativo, a través de actividades lúdicas atractivas e interesantes con un manejo de un lenguaje accesible, ameno y claro para que los visitantes sean estos locales, nacionales o extranjeros puedan conocer la riqueza cultural del sector.

3. Motivar el desarrollo reflexivo y la interpretación personal sobre las experiencias vivenciadas, propiciando una interacción que motiva el cuidado, valoración y conservación del lugar.

Los pilares operativos de un proceso de interpretación cultural, deben basarse en un enfoque sostenible, por lo cual el especialista cultural Jorge Morales, propone el empleo de la siguiente fórmula:

- $\mathrm{CR}$ - Conocimiento del recurso que va a ser interpretado. 
- $\mathrm{CD}$ - Conocimiento del público objetivo destinatario, que acudirá al centro de interpretación.

- TA - Técnicas Apropiadas, de acuerdo a la naturaleza del visitante.

- OI - Traducido en oportunidades de interpretación adaptadas y consensuadas.

Formándose la siguiente ecuación:

$$
(\mathrm{CR}+\mathrm{CD}) \times \mathrm{TA}=\mathrm{OI}
$$

El conocimiento del recurso, el descubrimiento de su esencia, es el punto de partida, que requiere complementarse con un buen conocimiento de las personas o grupos objetivos que serán los destinatarios de la interpretación, a través del manejo de técnicas comunicativas e interpretativas acertadas, que hagan que la experiencia cultural del turista marque un referente cultural 1 por la experiencia vivenciada.

\section{Diagramación General del Proceso de Interpretación Cultural}

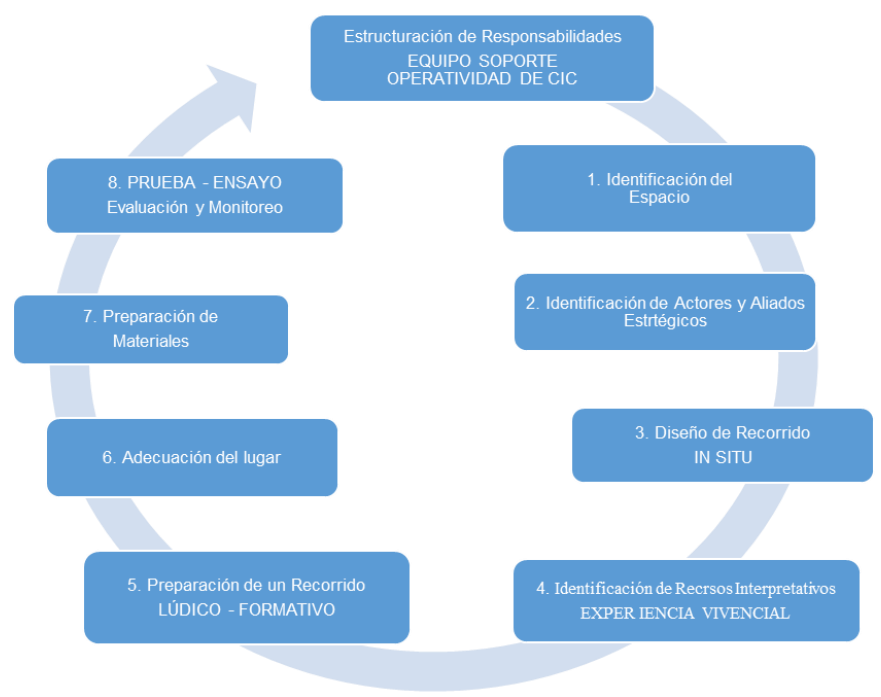

Figura Nro.11: Proceso de Interpretación Cultural

El tema de establecer un centro de interpretación cultural, requiere ser planificado y programado para que su puesta en marcha sea exitosa, el criterio primordial que debe prevalecer es la conservación cultural, a través de la comunicación de los saberes, el fortalecimiento de la identidad cultural, la valoración de las raíces étnicas de los pobladores del entorno, el reconocimiento de la urgencia de asumir actitudes de respeto, constitución de nuevo espacio de reflexión para la acción, responsabilidad y valoración, para lograr que el desarrollo del proyecto sea integral para promover el buen vivir, a través del aporte activo a la dinamización de la economía local, como un instrumento de desarrollo social, que abre sus oportunidades hacia nuevos enfoque y aportes multidisciplinarios que vinculan a una comunidad cultural con un público objetivo ávido de conocimiento.

Los clientes potenciales que podrían ser el grupo meta para visitar el centro de interpretación pueden ser identificados de la siguiente manera: 
a. Turistas Informales.- Personas que tienen la motivación de conocer un nuevo lugar con actividades interesantes que incrementen su conocimiento.

b. Grupos Familiares.- Núcleos motivados a realizar actividades distintas, vivenciando una nueva experiencia.

c. Investigadores Locales.- Personas locales de importante nivel formativo, que requieren realizar una visita IN SITU para incrementar conocimiento.

d. Investigadores Extranjeros.- Personas extranjeros de considerable y reconocido nivel académico formativo, que buscan sitios culturales para generar y fortalecer conocimiento.

e. Turistas Extranjeros.- Viajeros, profesionales, aventureros que tienen la convicción cultural de conocer nuevos entornos para incrementar su bagaje formativo a través de una experiencia vivencial.

Se podría señalar que la riqueza cultural de los pueblos originarios del sitio arqueológico de Ciudadeda (Tambokocha), se constituyen en una oportunidad de progreso de los pobladores actuales, a través de la investigación académica que determinará la creación de propuestas gráficas, enfocadas en difundir la riqueza ancestral y promover el desarrollo local de ésta zona, a través del diseño de souvenirs iconográficos de orden cultural cuya memoria histórica y proceso cultural pueden traducirse en la planificación y creación de un centro de interpretación turísticocultural, que pueda acoger a propios y foráneos para comunicar la sabiduría, creatividad y originalidad de nuestros antepasados como una herramienta de desarrollo que posee un valor formativo, que propicia la enseñanza y se constituye en un elemento de transmisión y apropiación de nuestras raíces e identidad, por otro lado, es la oportunidad de reactivar la economía de la zona, ya que el patrimonio ancestral, operado correctamente, puede crear empleo y negocio, convirtiéndose así en una importante fuente de ingresos. Finalmente, se pone de manifiesto el valor social, por contribuir a la puesta en valor del patrimonio y brindar una mejor calidad de vida de la población.

Existen iniciativas preliminares como la "Restauración Y Puesta En Valor De Las Viviendas Del Sitio Tambo Blanco (Tambokocha) - Ciudadela” (Burneo, 2003) en donde se puede advertir la potencialidad del mejoramiento de las viviendas vernáculas del lugar, en cuyo caso existe una política de incentivos de vivienda que el ministerio del ramo apoya con la concesión de un bono de mejoramiento que posibilitaría que los propietarios de las viviendas puedan proveer de condiciones mínimas de hospedaje y alimentación a los turistas interesados en conocer el sitio arqueológico y que permitiría aplicar la visión de turismo comunitario mencionada.

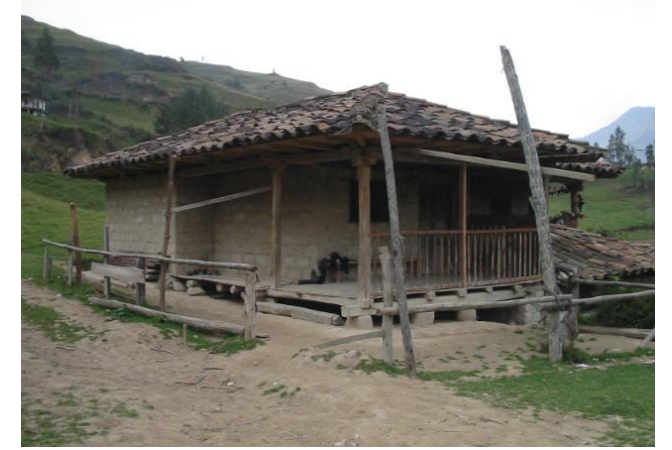

Figura Nro.12: Vivienda Vernácula de San Lucas. Fotografía de los autores 
En definitiva, para poder llevar a cabo proyectos de turismo cultural , es necesario llevar a cabo una correcta planificación, teniendo en cuenta el público al que irá dirigido y tratando de presentar los recursos como un todo, relacionándolos con el entorno en el que se sitúan, y realizando una interpretación adecuada, garantizando, a su vez, un desarrollo sostenible, de manera que se satisfagan las necesidades de las generaciones del presente pero sin influir negativamente en la satisfacción de las necesidades de las generaciones futuras (Rausell, 2014).

\section{Bibliografía}

Brun, H. Z. (2009). Acercamiento a la visión cósmica del mundo Andino. Punto Cero. Universidad Católica Boliviana, 14(18), 83-89.

Burneo, J. (Agosto de 2003). researchgate. Obtenido de researchgate: https://www.researchgate.net/publication/305933159_Turismo_Etnocultural_Arqueologic o_Autosustentable_Restauracion_Y_Puesta_En_Valor_De_Las_Viviendas_Del_Sitio_Ta mbo_Blanco_Tambokocha-_Ciudadela

Chañi Choquemaque, M. (2017). La metodología Lean Startup en la Empresa Munanqui Peruvian Tea, Arequipa 2017.

Còrdova, C., \& Daniel, F. (2016). La obra precolombina de la cultura Palta desde la filosofía Andina: propuesta 'estética'de armonización dinámica (Master's thesis).

Criado, E. A. (2007). Productos locales, mercados. Perspectivas teóricas en desarrollo local, 145.

Guamán Guamán, D. M. (2017). Diseño arquitectónico de un centro de Interpretación Intercultural para el sitio arqueológico Tambo Cocha, conceptualizado desde la cosmovisión de la cultura originaria del lugar, parroquia San Lucas, cantón Loja (Bachelor's thesis, QUITO/UIDE/2017).

Milla Euribe, Z. (1990). Introducción a la semiótica del diseño andino precolombino.

Milla Villena, C. (2003). Ayni: Semiótica andina de los espacios sagrados.

Morales, J.F. (2001). Guía Práctica para la Interpretación del Patrimonio - El Arte de Acercar el Legado Natural y Cultural al Público Visitante. España: Andalucía. TRAGSA S.A.

Morales, J.F. (2008). El sentido y metodología de la interpretación del patrimonio. En: Santos Mateos Rusillo (coord.), La comunicación global del patrimonio cultural. España: Gijón. TREA Ediciones.

Muchavisoy, J., \& Narciso, J. (1997). Los saberes indígenas son patrimonio de la humanidad. Nómadas (Col), (7).

OMT, 1995, Evaluación de los recursos turísticos culturales.

Rausell, P. (2014). Patrimonio y Empleo. España: Andalucía. LECU. 
Sacha, F. S. (2014). Artesanía de los Pueblos Ancestrales en la Mitad del Mundo: Ecuador. Quito: Fundación Sinchi Sacha.

Vera, F. \& Dávila, M. (1995). “Turismo y patrimonio histórico cultural”, España. Estudios Turísticos. 